\title{
El griego clásico y su incidencia en el léxico jurídico forense del siglo XXI
}

\section{Ancient Greek and its influence on the XXI century forensic legal lexicon}

\author{
Gerardo Francisco Ludeña González \\ Doctor en Gestión Pública y Gobernabilidad \\ Universidad César Vallejo, Lima - Perú \\ Correos electrónicos: ludena.gf@pucp.pe, gludenag@ucv.edu.pe \\ https://orcid.org/0000-0003-4433-9471

\begin{abstract}
David Efraín Misari Torpoco
Abogado

Escuela Iberoamericana de Postgrado y Educación Continua - ESIPEC, Lima - Perú

Correo electrónico: hphraim@gmail.com

https://orcid.org/0000-0001-8816-6715
\end{abstract}

\section{Violeta María De Piérola García \\ Magíster en Derecho \\ Universidad César Vallejo, Lima - Perú}

Correo electrónico: violetadepierola@gmail.com

https://orcid.org/0000-0002-8075-0340

\section{Waldemir Walter Ayala Ríos}

Educador, con especialidad en lengua inglesa

Universidad Católica Sedes Sapientiae, Lima - Perú

Correo: waldemirayala@gmail.com

https://orcid.org/0000-0002-7680-7906 


\section{Resumen}

Como profesionales del derecho sabemos que el lenguaje jurídico técnico contiene la esencia de los términos procedentes del latín, en razón de que el derecho se institucionalizó en Roma; sin embargo, existe un grupo de palabras que no tiene sus orígenes en el latín, sino en el griego clásico, cuyo conocimiento es necesario para aplicarlas a los textos jurídicos.

Mediante un análisis filológico e histórico se puede profundizar en la etimología y rastrear el origen del término griego que el derecho incorporaría en su vocabulario.

En el presente artículo científicamente se esboza la etimología, la definición y la aplicación actual de algunos vocablos jurídicos de origen griego con el animus de motivar al lector y en especial al letrado en su utilización por la nobles causas del derecho (orabunt causas mellius).

\section{Palabras clave}

Helenismo jurídico, griego clásico, vocabulario jurídico, etimología, lenguaje jurídico.

\section{Abstract}

As legal professionals we know that the technical legal language contains the essence of terms originated in Latin, due to law being institutionalized in Rome; however, a group of words exists that does not have their origins in Latin, but in Ancient Greek, whose knowledge is necessary to apply them to legal texts.

By the means of a philological and historical analysis, it is possible to get deeper into etymology and trace the origin of the Greek term that law would incorporate within its vocabulary.

This paper scientifically outlines the etymology, the definition, and current-day use of some words of Greek origin with the aim of motivating the reader, and particularly the lawyer, on their use for the noble causes of law (orabunt causas mellius).

\section{Key words}

Legal Hellenism, Ancient Greek, legal vocabulary, etymology, legal jargon.

\section{Cómo citar este artículo:}

Ludeña, G., Misari, D., De Piérola, V., \& Ayala, W. (2020). El griego clásico y su incidencia en el léxico jurídico forense del siglo XXI. Revista de la Facultad de Derecho y Ciencias Políticas, 50 (133), pp. 356-372.

doi: http://dx.doi.org/10.18566/rfdcp.v50n133.a06

Recibido: 16 de mayo de 2019.

Aprobado: 01 de 0ctubre de 2019. 


\section{Introducción}

\section{Problema de investigación}

El problema de investigación es el fundamento y materia prima básica para el inicio del presente artículo científico y proviene de la identificación de las notorias deficiencias de nosotros los letrados abogados con respecto a la utilización de un lenguaje jurídico técnico, específicamente los términos procedentes del latín. Además, se trata de conocer la terminología latina y de utilizar el griego clásico, cuyo conocimiento es necesario para ser aplicada en la argumentación jurídica de las resoluciones judiciales y en los informes orales, además de las cátedras de derecho romano y textos jurídicos afines.

\subsection{Aproximación temática}

La esencia de los términos procedentes del latín estudiados en la asignatura de derecho romano son de vital importancia para conocer el contexto etimológico, pragmático y científico del derecho, razón de ser de la alocución jurídica institucionalizada desde Roma. Sin embargo, es interesante puntualizar que existe un grupo de palabras que no tiene sus orígenes propiamente en el latín sino en el griego clásico, esto implica como objetivo de la presente investigación conforme refiere además Ramos (2016) el de identificarlas y determinarlas como aporte del conocimiento jurídico cultural del derecho, a ser utilizada en una defensa técnica, en la redacción y argumentación coherente, tanto en la motivación como en la fundamentación de las resoluciones judiciales, en el contexto de un debido proceso.

En el presente artículo científico se realiza un esbozo filológico e histórico con el fin de motivar al lector y en especial al letrado en su utilización por las nobles causas del derecho (orabunt causas mellius). Por consiguiente, se busca acotar científicamente la etimología del término griego que importa al derecho y, además, determinar el grado de relevancia. Esto permite la aplicación de vocablos jurídicos de origen griego tanto en la currícula de estudios universitarios de la carrera de derecho, como en el vocabulario personal del profesional letrado en el ejercicio oralizado y escriturado del patrocinio del justiciable.

\subsubsection{Problema general}

¿Cómo se explicita la conveniencia, relevancia, implicaciones prácticas y pertinencia del conocimiento y uso de los vocablos griegos, como cultura 
jurídica, frente a la argumentación jurídica de resoluciones y la sustanciación de una defensa técnica del letrado en favor del justiciable?

\subsubsection{Problema específico}

¿Qué significación científica relevante importa al derecho el estudio e incorporación de términos griegos tanto en la currícula universitaria, como en el vocabulario personal del profesional letrado en el ejercicio oralizado y escriturado del patrocinio del justiciable?

\subsubsection{Objetivo general}

Evidenciar la trascendencia de los vocablos griegos implícitos en la argumentación jurídica de resoluciones que coadyuvan en la sustanciación de una defensa técnica del letrado en favor del justiciable.

\subsubsection{Objetivos específicos}

Analizar la cientificidad e identificación etimológica del porqué de su existencia y aporte jurídico, que importa al derecho respecto del estudio e incorporación de términos griegos, en los textos jurídicos, en el sílabo universitario de la carrera de derecho o del curso afín de historia del derecho u otros $\mathrm{y}$, en el ejercicio de sustento jurídico de la defensa técnica de los profesionales del derecho.

\subsubsection{Método}

La métodología del presente artículo resulta básica, (Valderrama, 2015 p.76), dado el análisis de textos afines para identificar y resaltar la conveniencia de estudio, conteniendo teoría fundamentada en su diseño, con el propósito de motivar la incorporación en el léxico jurídico tanto sistémico como diádico como parte de la transparencia e idoneidad del ejercicio profesional en un Estado de derecho y la calidad del profesional, en cuanto a su oratoria forense y cultura jurídica.

Los objetivos son claros en todo caso, se circunscriben en la identificación etimológica del porqué de su existencia y aporte jurídico, además de la determinación de su incorporación en los textos jurídicos como derecho griego en el sílabo universitario de la carrera de derecho y en el ejercicio de sustento jurídico de la defensa técnica de los profesionales del derecho. 
Como se recalca, el presente artículo científico resulta relevante, pues busca motivar y generar corriente de opinión que justifique la conveniencia, relevancia, implicaciones prácticas y pertinencia del conocimiento y uso de los vocablos griegos, como sustento de defensa técnica del letrado tanto para el ejercicio de su profesionalismo bajo una defensa técnica y argumentación jurídica adecuada en las resoluciones judiciales, como por su cultura jurídica.

\section{Desarrollo}

\section{Introducción a la terminología griega jurídica}

El uso de los términos es pieza fundamental para los escritos que realizamos a diario, sea como abogados independientes o como empleados de alguna entidad pública o privada. Desde nuestra visión de investigadores consideramos que, aunque el derecho en la actualidad contiene más de cuatro mil palabras técnicas, no todas son conocidas; mientras que la gran mayoría procede del latín.

El derecho tal y como lo conocemos en la actualidad, conforme lo menciona Hernández: "es el resultado de un proceso evolutivo histórico de miles de años, desde la aparición de la especie humana que sin embargo tiene sus inicios en Roma”(Hernández, 2013, p.228).

A lo largo de su historia, destacados abogados y jurisconsultos romanos fueron preparados en la lengua griega. Tal es el caso de Cicerón, según García (1979) en su obra ¿Cicerón y Horacio preceptistas de la traducción? menciona que Cicerón desde su juventud aprendió y dominó el griego, razón por la cual podía leer sin dificultad obras escritas en la lengua de Platón.

Signes (2013) menciona que, "en la época de Justiniano, todavía se analizaban varios papiros jurídicos escritos en lengua griega desde una óptica paleográfica”. (p. 98).

En la antigua Roma, mientras que los gramáticos reconocían solamente al griego como la lengua del aprendizaje y de la literatura, se tiene que un liberto de Titus Pomponius Atticus (Tito Pomponio Ático), que responde al nombre de Quintus Caecilius Epirota (Quinto Cecilio Epirota), fue el primer gramático en presentar lecciones de temas latinos leyendo a Virgilio y a otros poetas romanos coetáneos. Si bien esto escandalizó a Roma en un inicio, demostró 
que en el imperio el latín estaba en pie de igualdad ante el griego, como lengua vehicular en todos los ámbitos, incluida la retórica. Desde entonces, se inició una competencia entre ambas lenguas que no se detendría más adelante.

Desde el aporte cronológico de nuestra investigación cabe señalar que, como consecuencia, la primera escuela de retórica latina fue abierta por Lucius Plocius Gallus (Lucio Plocio Gallo), quien rompió la continuidad de las escuelas de retórica que impartían sus clases en lengua griega únicamente. Esto era una muestra de que no había ya que pasar por la lengua internacional para iniciarse en el arte oratorio sino que bastaba la lengua nacional. Esto representó en cierto modo un alivio, porque la teoría de la elocuencia helena suponía un innecesario esfuerzo doble para los estudiantes romanos, cuyo programa de estudios podía contener hasta la mitad sobre los clásicos griegos.

A decir de García: “a diferencia de los romanos, sus pares orientales no hacían más que estudiar su lengua materna” (1979, p.148).

De esta manera, los romanos reivindicaron su propia identidad cultural, al ahondar en Cicerón y Virgilo, ilustres jurisconsultos, y al imitar tanto a Quintiliano cuanto a Plinio el Joven, ambos con una esmerada educación en griego. Es por esto que podían citar a los clásicos helenos, si bien con mucha menor frecuencia tal cual puede advertirse en sus obras.

De ahí en adelante, se evidencia ya un decaimiento y continúa la desmejora de la calidad de la enseñanza de la lengua de Homero, se mantuvo aún mejor en unos campos que otros, como en la medicina y la filosofía.

En la filosofía es menester citar a Boëthius (Boecio), último usuario de un excelente griego en la Italia del siglo VI. Las familias aristocráticas, como aquella en la que él nació, debido a su afán conservador, supieron mantenerse fieles a esa antigua tradición griega que acabó siendo desplazada por el latín en Occidente. En este contexto donde la filosofía griega se encuentra en un Occidente ya latinizado, emergieron los ius prudentes (los sabios por prudentes del derecho), quienes se agenciaron de las obras griegas por medio de doxografías, anécdotas, apotegmas y florilegios (nótese que florilegia no es

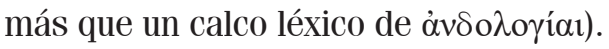

Entre los siglos V al XVI, época del derecho medieval, algunos juristas debieron manejar el griego para escribir sus obras en latín y, a la vez, comparar con fuentes directas varios términos jurídicos que los autores clásicos dejaban 
en sus escritos. En el siglo XVII, Hugo Grocio fue quien también empleó el griego, tal como muestran las citas del griego clásico en obras como De iure belli ac pacis, cuando escribe extractos de Hesíodo, Heráclito, Aristóteles, Eurípides, entre otros autores griegos. Pero Grocio no fue el único jurista del siglo XVII que recurrió al griego. John Selden (1584-1654), jurista inglés, empleó además del latín (lengua universal en aquella época), el griego, el hebreo y el árabe clásico. (Batchelor, 2014, pp.128-151).

En cuanto a la incidencia virtual de búsqueda de libros dedicados a la enseñanza de la terminología latina, con respecto al tema sub limine referido al léxico jurídico forense del siglo XXI, en la actualidad hay marcadas limitaciones en la búsqueda en internet, no nos referimos precisamente a los diccionarios jurídicos en donde podemos encontrar algunas locuciones latinas y aforismos sino a textos que íntegramente trabajan el latín jurídico, esto se nota al comparar la búsqueda del "latín jurídico libro" y el "griego jurídico libro" advirtiéndose en el primero de los casos que el buscador le arrojará varios resultados; no obstante, no sucede lo mismo si usted escribe "griego jurídico libro”, ya que lo único que saldrá serán textos de derecho que aluden a las leyes en Grecia o, simplemente, otro tipo de información que no tiene nada que ver con un texto íntegro sobre el lenguaje jurídico griego y si nos situamos en un contexto no jurídico, tanto el griego como el latín abundan en nuestra lengua castellana, no solo nos referimos a los prefijos o sufijos, sino a muchas palabras de nuestro vocabulario que los contienen.

Precisamente a estas palabras que proceden de la lengua griega se les denomina helenismos. En singular, helenismo tiene, cuando menos, tres acepciones: civilización del período helenístico (323-30 a. C.), adopción por admiración de la antigua cultura griega y modismo heleno. El término, como tal, aparece en Histoire de l'hellénisme , obra traducida al francés del original Geschichte des Hellenismus , escrito por el historiador alemán Johann Gustav Droysen.

De un análisis de la incidencia al tema sub limine referido al griego clásico, en cuanto modismo heleno como léxico jurídico forense, este tiene su origen en

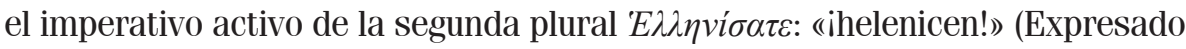

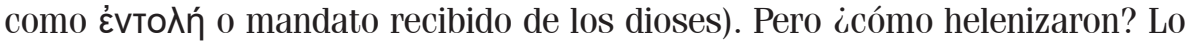
hicieron, verbi gratia, a través de exónimos, tal cual es constatado en el libro

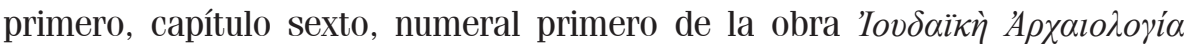
(traducido como Antigüedades judías por su versión latina Antiquitates

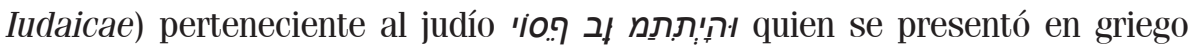




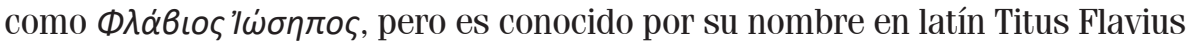
Iosephus, que traducido a nuestra lengua fue Flavio Josefo.

Su nombre hebreo completo es José hijo de Matatías, traducido a la lengua nuestra. Sépase que la fórmula (hijo de» + (nombre del padre» es el equivalente antiguo de la forma moderna de apellidarnos.

Ahora bien, habría que averiguar la razón de que se le llame Josefo, pues en hebreo sería Josef /yoséf/. Cuando helenizó su nombre, añadió la terminación griega os, que pasa como o a nuestra lengua. Además, se llamó Flavio debido al nomen, esto es, el (apellido paterno») de Titus Flavius Vespasianus (Tito Flavio Vespasiano), emperador que lo liberó dos años después de haber caído como

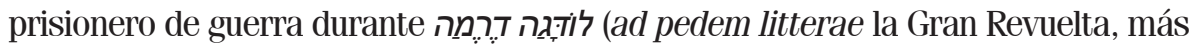
conocida como la Primera Guerra Judeo-Romana. Vespasiano lo dejó en libertad, porque en aquella guerra Josefo había vaticinado que aquel devendría Emperador.

Josefo, en calidad de historiador, prosiguió la metodología gráfica de

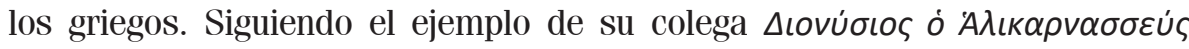

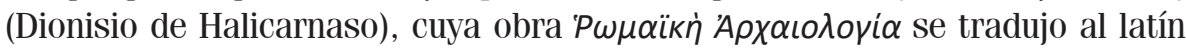
como Antiquitates Romanae (Antigüedades Romanas), Flavio Josefo escribió Antigüedades Judías, una de sus cuatro obras junto con O Bios (La vida)

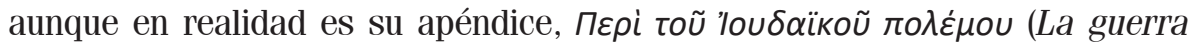

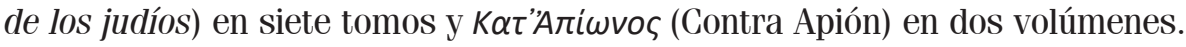
Cronológicamente, Antigüedades judías es la segunda obra suya, dado que fue redactada veinte años después de La guerra de los judíos.

Josefo mostró al mundo helenizado el judaísmo desde sus albores hasta los de la Primera Guerra Judeo-Romana, echando frecuentemente mano de

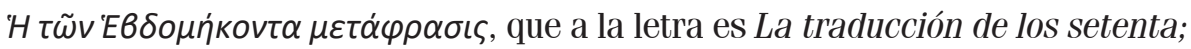
pero llamada llanamente La Septuaginta (por influencia de su versión latina Septuaginta, literalmente 'setenta') o bien abreviada LXX.

Este célebre personaje, una vez granjeada su ciudadanía romana (si bien no aprendió el latín debido al griego que era la otra lengua que hacía bilingüe al imperio), obtuvo una pensión por la que llegó a residir de por vida en el palacio imperatorio no solo de Vespasiano, sino también de los emperadores subsiguientes: su hijo mayor Titus Flavius Sabinus Vespasianus (Tito Flavio Sabino Vespasiano) y su hijo menor Titus Flavius Domitianus (Tito Flavio Domiciano), aunque este último no mostró gran interés por la literatura escrita por su patrocinado. 
Así, tomó la resolución de no más retornar a su tierra, por lo que sus coterráneos decidieron, sin conocimiento explícito, aplicar una figura romana denominada damnatio memoriae (mírese Dissertationem Iuridicam de Damnatione Memoriae sub praesidio Dn. Christophori Schreiteri, U.J.D. M.DC.LXXXIX. Lipsiae; Tesis sobre la condena del recuerdo a ser sustentada por el Sr. Christoph Schreiter para Doctor en Derecho Civil y Canónico, 1689, Leipzig, Alemania) que consistía en omitir su nombre de la literatura rabínica por completo.

Esta misma medida la habían aplicado anteriormente a su paisano el filósofo

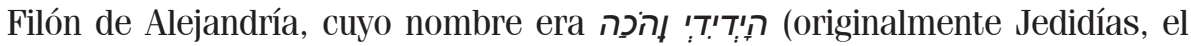
sacerdote), en griego $\Phi i \lambda \omega v$ toũ 'A $A \varepsilon \xi \alpha v \delta \rho \varepsilon i \alpha \varsigma$, a quien Flavio Josefo citó en Antigüedades Judías. Con esta obra Josefo a su vez testimonió que sus conterráneos no sabían griego, lo que convirtió a Josefo en un judío conspicuo tanto como Filón. Ambos fueron los ínclitos transmisores de su literatura al mundo de entonces.

Recapitulando, el historiador de antes era en esencia un escritor sobre los hechos que atestiguaba cuando acompañaba al emperador, así como el reportero de ahora informa desde el sitio donde un evento tiene lugar.

Entre otros, cabe acotar que el Diccionario de la Real Academia Española para definir el término helenismo nos ofrece dos acepciones:

1) Modo de hablar o giro propio y privativo de la lengua griega.

2) Empleo de construcciones o giros en otro idioma.

En otras palabras, los helenismos lo constituyen aquellas palabras que proceden directamente del lenguaje griego y se usan en otras lenguas, cabe precisar en todo caso que, en nuestra lengua castellana, los helenismos se encuentran por lo general en la terminología científica y en ciertas palabras técnicas; empero, algunos de ellos fueron traducidos o tomados por los antiguos romanos para latinizarlos. Aun así, debemos tener siempre cuidado al momento de reconocer una palabra como propia del latín o del griego, ya que en varias ocasiones los romanos recurrían al calco léxico. En otras palabras, copiaban la estructura de la palabra griega y traducían las palabras más o menos literalmente a su propia lengua latina. De este modo, la palabra griega $\mu \varepsilon \tau \alpha \mu o ́ \rho \varphi \omega \sigma \iota \varsigma$ (metamorfosis) sería copiada y traducida en latín como transformatio, (gr. meta $=$ lat. trans y gr. morfo $=$ lat. forma $)$. 


\subsection{Estudio de los prefijos griegos}

Es importante tener presente la tabla 1 adjunta, donde consignamos los prefijos griegos que se han incorporado a nuestro lenguaje como aporte del griego a nuestra lengua.

Tabla 1: Prefijos griegos adaptados al español

\begin{tabular}{|c|c|c|c|}
\hline $\begin{array}{l}\text { Prefijo en } \\
\text { griego }\end{array}$ & $\begin{array}{c}\text { Prefijo } \\
\text { (castellano) }\end{array}$ & Significado & Palabra \\
\hline$\dot{\alpha}-/ \dot{\alpha} v-/ \dot{\alpha} \mu v-$ & a- / an- /amn- & sin / carente de & ácrata/anarquista/amnistía \\
\hline áva- & ana- & contra / sobre & anatocismo \\
\hline$\dot{\alpha} \mu \phi \dot{-}$ & anfi- & alrededor/ doble & anfiteatro/anfibología \\
\hline$\alpha v t i-$ & anti- & contra & anticresis \\
\hline ф́ло- & apo- & fuera de & apócrifo/apología \\
\hline ópxt- & archi- & el más/mejor & archirrival/archimillonario \\
\hline aủtó- & auto- & uno mismo & autómata/autosuficiente \\
\hline како- & caco- & desagradable & cacofonía/cacodemonio \\
\hline катó- & cata- & hacia abajo & cataclismo/catarata \\
\hline$\delta\llcorner\alpha-$ & dia- & a través de & diácono/diapositiva \\
\hline Suৎ- & dis- & con dificultad & discordante/disputa \\
\hline$\varepsilon \kappa \tau о-$ & ecto- & fuera de & ectoplasma \\
\hline ह̌vઠo- & endo- & internamente & endogamia/ endógeno \\
\hline$\dot{\varepsilon} \pi \mathrm{l}-$ & epi- & sobre & epidemia/epilepsia \\
\hline$\varepsilon \dot{-}-$ & eu- & bien & eutanasia \\
\hline$\ddot{\varepsilon} \xi \omega-$ & exo- & fuera & exógeno \\
\hline$\dot{\eta} \mu \mathrm{t \sigma}-$ & hemi- & medio & hemisferio/hemistiquio \\
\hline ن்rદ́p- & hiper- & exceso o sobre & hipertensión/hipermercado \\
\hline ن்ró- & hipo- & debajo & hipoteca \\
\hline เซo- & iso- & igual & isotermo \\
\hline$\mu \varepsilon \tau \alpha-$ & meta- & más allá de & metafísica/metabolismo \\
\hline 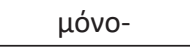 & mono- & uno & monoteísmo/monocorde \\
\hline$\pi \alpha ́ \lambda ı$ เ & palin- & de nuevo & palíndromo \\
\hline$\pi \alpha \rho \alpha-$ & para- & junto con & paráfrasis/parafernales \\
\hline$\pi \varepsilon \rho \iota_{-}$ & peri- & alrededor & periférico/ perímetro \\
\hline$\pi \rho o_{-}$ & pro- & delante/antes & prólogo/prótesis \\
\hline ouv- & sin- & con & sinalagmático \\
\hline
\end{tabular}

Fuente: Elaboración propia. 
La identificación de los prefijos citados a partir del presente artículo explicita la razón de su existencia y la importancia de conocerlos, al considerar además la incidencia y significación para el abogado como lenguaje técnico jurídico.

\section{Avance de significación y trascendencia de los términos jurídicos procedentes del griego clásico en la actualidad}

De varias palabras latinas que han sido incorporadas y permanecen en nuestro léxico jurídico, se identifican las citadas del griego clásico que no solo evidencian su existencia sino que dan a relucir el significado de las mismas como terminología jurídica, en tanto proviene etimológica e históricamente del vocablo que ha llegado hasta nuestros días, es por ello que, realizada una selección de términos jurídicos procedentes de la lengua griega -aunque la mayoría de ellos ingresaron por el latín- resulta interesante conocerlas y hacerlas vigentes en la actualidad. A estos términos se les denomina helenismos jurídicos.

\section{1. Ácrata}

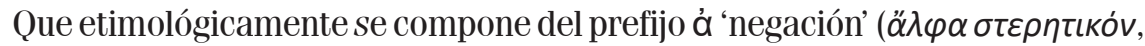

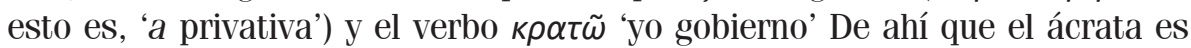
un desgobernado, como lo fue "Акратоৎ (Ácrato), quien -de acuerdo con el

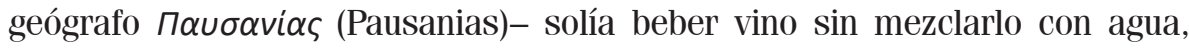
como era consuetudinario. En inglés, es traducido como anarchist, mientras

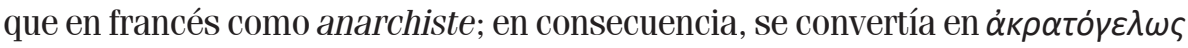

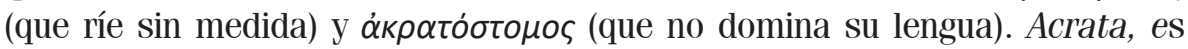
"aquel partidario que está de acuerdo con la supresión de toda autoridad" (Alcaraz, Hugues y Gómez, 2016, p. 36).

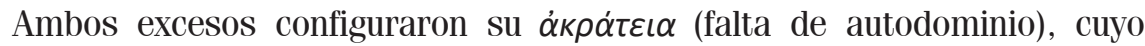

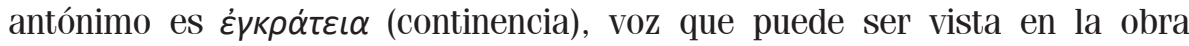

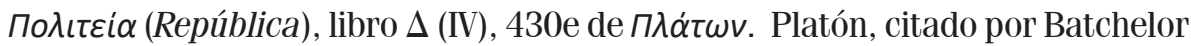

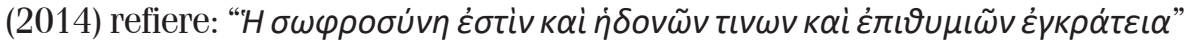
(«La sobriedad es también autocontrol sobre ciertos placeres y deseos»). (pp.140-151) 


\subsection{Amnistía}

Etimología: Se compone del mencionado prefijo ả negación y el verbo $\mu \iota v \eta \dot{\sigma} \kappa \omega$ : yo recuerdo. Consecuentemente, entiéndase literalmente la amnistía como "no recuerdo". La fórmula amnistial $\mu \dot{\eta} \mu v \eta \sigma i k \alpha \kappa \varepsilon \tilde{v}$ (no recordar lo malo)

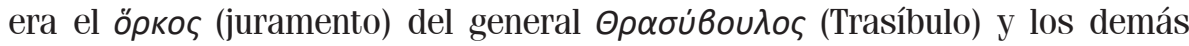
demócratas atenienses para soslayar cualesquiera intentos de venganza

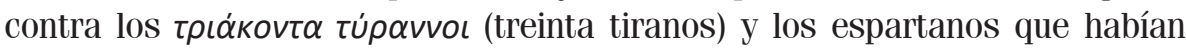
vencido durante la Guerra del Peloponeso.

De este modo, la amnistía fue instrumentalizada a fin de recuperar la

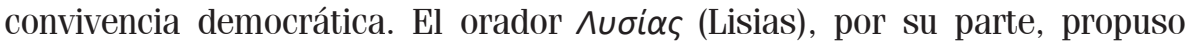
"recordación" en lugar de una indiscriminada aplicación de la protección

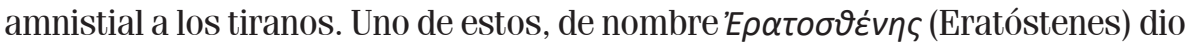

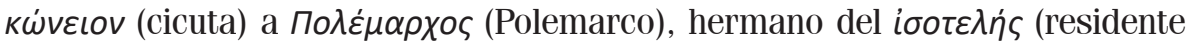
extranjero) Lisias. En inglés es traducido como amnesty, mientras que en francés es amnistie.

- Definición 1: "Refiérase al perdón de algunos delitos que son de naturaleza política, decretado por el gobierno de una nación” (Alcaraz, Hugues y Gómez, 2016, p. 36).

- Definición 2: Perdón y olvido de delitos generalmente políticos. Es un medio frecuente de conciliación política que se concede usualmente al momento de cambios de gobierno. Típicamente no es un perdón, sino un olvido. Al ser olvidado el delito, queda borrado y en consecuencia no aparece en los antecedentes penales del amnistiado. "La amnistía se otorga por medio de una ley". (Ezaine, 1973, p. 22).

- Definición 3: "Forma de ejercicio del derecho de gracia que corresponde a los poderes públicos” (Muñoz, 2017, p. 228).

\subsection{Anatocismo}

Etimología: Está conformado por el prefijo áva mejoramiento y el sustantivo masculino то́коц interés. En inglés anatocism /compounding of interest. En francés anatocisme.

Así pues, el anatocismo es el mejoramiento del interés, tal cual queda testimoniado en el libro V, 21 de la obra Epistulæ ad Atticum (Epístolas a Ático) de Marcus Tullius Cicero (Marco Tulio Cicerón) quien -debido a su formación 


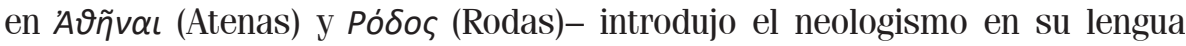
materna: Interim, cum ego in edicto translaticio centesimas me observaturum haberem cum anatocismo anniversario "Mientras tanto, en el edicto mío, había fijado la tasa en doce por ciento de interés calculado al año”. (Batchelor, 2014, pp.140-145)

- Definición 1: Entiéndase como el interés de los intereses o interés compuesto. Además: "los intereses que fueron vencidos se agregan al capital para generar nuevos intereses, sea por convenio entre los interesados o por determinación legal”. (Muñoz, 2017, p. 228).

- Definición 2: "Dícese de la capitalización de los intereses que fueron vencidos de una deuda” (Alcaraz, Hugues y Gómez, 2016, p. 36).

\subsection{Anticresis}

Etimología: Está formado a partir de la preposición óvií a cambio de y

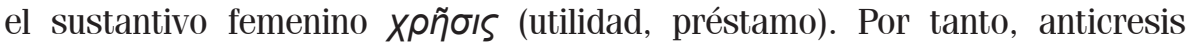
significa: a cambio de la utilidad o del préstamo. En latín antichresis; en inglés antichresis; francés antichrèse; italiano anticresi; portugués anticrese y alemán antichrese. Citado por Batchelor (2014) acotando al corpus Iuris Civilis, en el libro XX, 1, 11, 1 de la obra Digesta (Disposiciones) de Iustinianus (Justiniano). (p.150)

- Definición 1: "Por la anticresis se entrega un inmueble en garantía de una deuda, concediendo al acreedor el derecho de explotarlo y percibir sus frutos”, Código Civil del Perú, artículo 1091 (1984).

- Definición 2: "Dícese del contrato o acto procesal por el que se entrega al acreedor un bien raíz para que se cobre su crédito con los frutos que perciba” (Couture, 1976, p. 95).

- Definición 3: "Es un contrato en que el deudor consiente en que su acreedor goce de los frutos de la finca que le entrega en garantía hasta que sea cancelada la deuda” (Alcaraz, Hugues y Gómez, 2016, p. 36).

\subsection{Democracia}

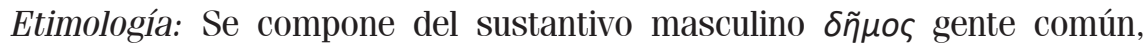

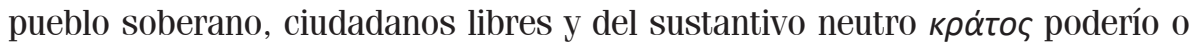
fuerza. En inglés democracy; francés démocratie. 
Así, democracia es el poderío de la gente común, fuerza de los ciudadanos

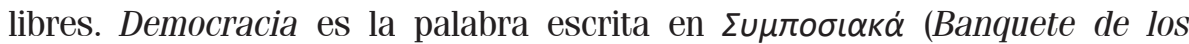

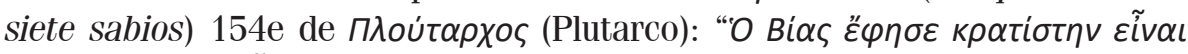

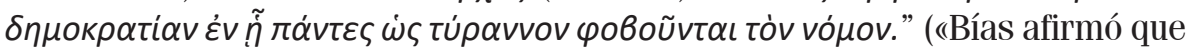
la democracia más fuerte es en la que todos temen la ley como a un tirano»). (Batchelor, 2014, pp.145)

- Definición 1: "Es el gobierno en el que los gobernantes fueron elegidos por los ciudadanos mediante una votación” (Alcaraz, Hugues y Gómez, 2016, p. 36).

- Definición 2: "Refiérese al régimen político mediante el cual el poder viene del pueblo y se ejerce por él y para él, sea directa o indirectamente” (Ramírez, 1942, p.101).

\subsection{Enfiteusis}

Etimología: Se construye con la preposición év en y el verbo $\varphi u ́ \omega$ yo doy a luz, por lo que el verbo $\varepsilon \mu \varphi u ́ \omega$ y la palabra en cuestión se entienden como yo implanto, yo infundo. El término enfiteusis puede ser leído en Novellæ Constitutiones (Nuevas constituciones 55,2) de Iustinianus (Justiniano). En latín emphyteusis; inglés emphyteusis. En francés emphytéose.

En lengua latina, el adjetivo femenino plural novellæ está en nominativo

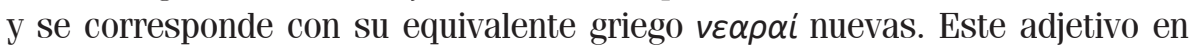
singular en latín es novella, formada a partir del adjetivo nova nueva y el sufijo -ella diminutivo, cuyo significado es nuevecita. A partir del siglo VI, novella (nuevecita, novísima, reciente) designó por antonomasia una ley promulgada por un emperador bizantino. Queda el mismo sentido en el inglés novels, que tomó del francés novelles, el cual a su vez tomó del latín novellæ.

En el derecho romano es menester poner parte de la historia que existe detrás de este término, para lo cual citamos:"El antecedente de la enfiteusis data de la época más remonta del derecho romano, cuando el Estado daba en arrendamiento, terrenos agrícolas de su propiedad a perpetuidad, figura que se conoció como ius in agro vegtigali” (Morineau, 2006, p. 53).

- Definición 1: "Refiérase al contrato por el cual se cede a perpetuidad o largo tiempo el dominio útil de un inmueble mediante el pago anual de una pensión o canon. También podría ser entendida como un derecho real censualista a 
la obtención del canon a que está sujeto el bien cedido en enfiteusis, y del enfiteuta a su dominio útil” (Muñoz, 2017, p. 275).

- Definición 2: "Está referida a la cesión perpetua o por largo tiempo del dominio útil de un inmueble, mediante el pago anual de un canon, por cada enajenación del dominio" (Alcaraz, Hugues y Gómez, 2016, p. 36).

- Definición 3: "Derecho real por el cual se entrega para siempre, el dominio útil de un inmueble, reservándose el propietario su dominio directo a cambio del pago de un canon o pensión anual” (Ramírez, 1942, p. 101).

\subsection{Hipoteca}

Etimología: Viene del sustantivo femenino úroษท́кn garantía, depósito,

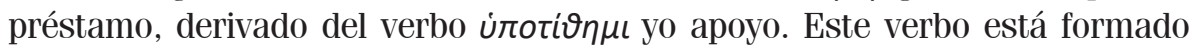
a partir de la preposición úró debajo de y el verbo tînnı yo pongo. En latín hypotheca. En inglés mortgage. En francés hypothèque. En italiano Ipoteca. En portugués hipoteca y en alemán hypotek.

El sustantivo que nos ocupa fue utilizado en la obra Katá Фopuíwvos (Contra

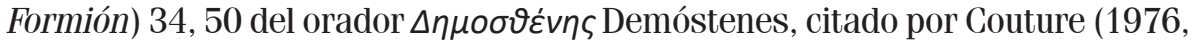
p. 314-315).

- Definición 1: A continuación veamos las distintas nociones para la palabra hipoteca que se encuentran en la obra de Couture (1976, p. 314-315):

1. Contrato accesorio por virtud del cual se afectan en garantía de una obligación y confiriendo preferencia al acreedor, determinados bienes raíces o naves, que no por eso dejan de quedar en poder del dueño.

2. Gravamen que afecta un bien inmueble o una nave en las condiciones establecidas en el contrato respectivo.

3. Derecho real contra la cosa, accesorio de un derecho de crédito, constituido por convención.

4. Medida cautelar otorgada en el proceso para garantizar los resultados del mismo o para asegurar el daño que pudieran producir otras medidas de cautela.

5. Escritura que registra la constitución de hipoteca.

- Definición 2: "Por la hipoteca se afecta un inmueble en garantía del cumplimiento de cualquier obligación, propia o de un tercero. La garantía no determina la desposesión y otorga al acreedor los derechos de persecución, 
preferencia y venta judicial del bien hipotecado" (Código Civil del Perú, 1984, artículo 1097).

- Definición 3: "Derecho real constituido en seguridad de un crédito en dinero sobre los bienes inmuebles, los cuales quedan en poder del deudor" (Ramírez, 1942, p. 150).

- Definición 4: "Gravamen que afecta a una finca u otra propiedad real, sujetándola a responder del pago de un crédito o deuda” (Alcaraz, Hugues y Gómez, 2016, p. 36).

\subsection{Sinalagmático}

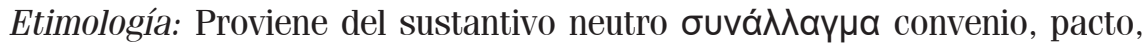

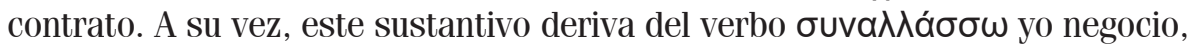

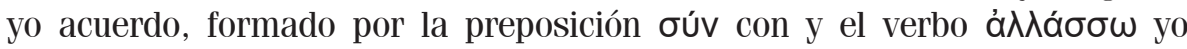
intercambio. En inglés synallagmatic. En francés synallagmatique.

De esta manera, sinalagmático significa relativo al contrato. El sustantivo antedicho fue desarrollado por el abogado romano Titius Aristo (Titio Aristón) a partir de su colega Marcus Antistius Labeo (Marco Antistio Labeón), como consta en la obra Digesta (Disposiciones) 50, 16, 19 de Iustinianus (Justiniano). (Batchelor, 2014,pp.149)

- Definición: "Acto jurídico que produce obligaciones recíprocas para las partes”, vgr: el contrato de compraventa (Ramírez, 1942, p. 246).

- Definición 2: "Aplicado al contrato, pacto o tratado bilateral en el que cada una de las partes queda comprometida a cumplir las condiciones u obligaciones establecidas” (Alcaraz, Hugues y Gómez, 2016, p. 36).

\section{Conclusiones}

Conforme la elocuencia de lo referido percibimos la real importancia de conocer cómo los vocablos griegos procedentes de la lengua de Aristóteles resultan interesantes en el contexto jurídico científico, lamentando que muchos letrados en su mayoría la desconocen, por no decir casi todos los profesionales y operadores del derecho, pese a que por cultura jurídica muchos vocablos han perdurado hasta nuestros días. 
De lo que podemos colegir finalmente que:

- Es evidente y se acredita a partir de la presente investigación, la importancia de los vocablos griegos procedentes de la lengua de Aristóteles en los textos de derecho histórico, los cuales resultan ser interesantes en el contexto jurídico científico, dado que la mayoría de los tecnicismos jurídicos proceden del griego como términos añejos aplicados en principio al estudio de la ciencia política y al derecho. En este sentido, se tienen palabras como: autarquía, monarquía, plutocracia, oligarquía, entre otros; cuya significación y prevalencia deben ser analizados tanto etimológica como política y jurídicamente.

- Es penoso señalar que la significación y trascendencia de los términos jurídicos procedentes del griego clásico en la actualidad es desconocida por la mayoría, por no decir por casi todos los profesionales y operadores del derecho.

- De varias palabras latinas que han sido incorporadas y permanecen en nuestro léxico jurídico, se identifican las citadas del griego clásico, que no solo evidencian su existencia sino que dan a relucir — por cultura jurídica - el significado de su terminología, en tanto proviene etimológica e históricamente del vocablo que ha llegado hasta nuestros días.

- Los denominados vocablos citados como helenismos jurídicos que en suma son ocho, aquellos citados resultan de interés para el estudiante de las aulas universitarias de la carrera de derecho y preferentemente para el operador de justicia y para el profesional del derecho, quienes deben considerar - como parte de su cultura jurídica - conocer de las lenguas clásicas y aprender tanto el latín como el griego clásico, con el objetivo de sugerir su incorporación en lo sílabos universitarios de derecho romano, como parte de la formación personal del profesional en derecho.

- Como colofón del presente artículo de investigación invitamos a una reflexión a los lectores a fin de evidenciar en el léxico griego un aporte más en procura del estudiante de derecho en las aulas universitarias y en el ejercicio del litigio y la defensa del justiciable, con el fin de ampliar su bagaje cultural y elocuente dentro de su defensa técnica añadida al léxico jurídico romano. 
- En todo caso - al igual que el latín jurídico - debería estudiarse y llevarse un curso de Griego Jurídico en las aulas universitarias, ya que resulta prevalente a partir de esta investigación científica exploratoria y preliminar, que los letrados, estudiantes de derecho, jurisconsultos y magistrados también conozcan, aunque fuere de manera básica, el griego clásico, siendo parte de su experiencia y cultura jurídica como se reitera, de tal sentido sean utilizados los términos griegos en procura de las nobles causas del derecho (orabunt causas mellius).

\section{Referencias bibliográficas}

Alcaraz, E., Hugues B. y Gómez A. (2016). El español jurídico. Editorial Ariel.

Batchelor, R. (2014). London: The Selden Map and the Making of a Global City. University of Chicago Press.

Couture, E. (1976). Vocabulario jurídico. Ediciones Depalma.

Ezaine, A. (1973). Diccionario de Derecho Penal. Ediciones Jurídicas Lambayeque.

García, V. (1979). ¿Cicerón y Horacio preceptistas de la traducción? . Cuadernos de Filología Clásica, Estudios Latinos,. 16,. Universidad Complutense de Madrid.

Hernández, M. (2014). Perdulario. Antología poética. Diputación.

Morineau, M. (2006). Diccionario de derecho romano. Editorial mexicana.

Muñoz, S. (2017). Libro de estilo de la justicia. Editorial Espasa.

Ramírez, J. (1942). Diccionario jurídico. Editorial Claridad.

Ramos, C. (2016). Cómo hacer una tesis de derecho y no envejecer en el intento. Grijley. Signes, J. (2013). El léxico jurídico griego desde Justiniano hasta hoy, en Seminarios Complutenses de derecho romano. Revista internacional de derecho romano y tradición romanística, 16. Marcial Pons.

Valderrama, V. (2015). Metodología de la investigación. (8ed.). Editorial San Marcos. 